\title{
Dynamic Overshoot Near Trench Caused by Large Asperity Break at Depth
}

\author{
EIICHI FukuYama ${ }^{1}$ and SÉBAstien HoK $^{2}$
}

\begin{abstract}
In an attempt to explain the large shallow slip that occurred near the trench during the 2011 Tohoku-Oki earthquake, numerical simulations of earthquake dynamic rupture were carried out using a fault model with a subduction interface containing a bump-shaped asperity, which might result from subduction of an old submarine volcano or seamount. It was assumed that during the interseismic period, slip only occurs outside the bump area and that stress accumulates inside the bump, creating a seismogenic asperity. We roughly evaluated the amount of slip outside the bump during the interseismic period, assuming a constant long-term subduction rate. Then we could estimate the accumulated stress inside the bump. We constructed the initial stress distribution based on the stress change caused by the slip-deficit distribution. A constitutive relation was constructed based on a slip-weakening friction law and was used to compute spontaneous ruptures. The results indicate that a large slip can occur between the trench and the bump, even though a very small amount of stress is accumulated there before the rupture. This is due to an interaction between the free surface and the fault that causes slip overshoot. On the region of the fault below the bump, such overshoot cannot occur because the fault is pinned by the deeper un-slipped zone. However, on the shallower side, the edge of the fault becomes free when the rupture approaches the free surface. In this region, such a large slip can occur without releasing a large amount of stress.
\end{abstract}

Key words: Earthquake rupture dynamics, non-planar fault, subduction earthquake, 2011 Tohoku-Oki earthquake.

\section{Introduction}

The 2011 Tohoku-Oki earthquake is one of the most important earthquakes for seismologists in many senses. From the viewpoint of earthquake source physics, this earthquake posed several as of yet unresolved questions. One such question concerns the slip

1 National Research Institute for Earth Science and Disaster Prevention (NIED), Tsukuba 305-0006, Japan. E-mail: fuku@bosai.go.jp

2 Institut de Radioprotection et de Sûreté Nucléaire (IRSN), PRP-DGE, SCAN, BERSSIN, 92260 Fontenay-aux-Roses, France. E-mail: sebastien.hok@irsn.fr distribution. A large number of slip models have been proposed based on many kinds of observations (e.g. OzAWA et al. 2011; SimOns et al. 2011; MiYAZAKi et al. 2011; НАSHIMOTO et al. 2012; IDE et al. 2011; YAGI and FuKahATA 2011; SUZUKi et al. 2011; LeE et al. 2011; SHAO et al. 2011; Yoshida et al. 2011; IsHII 2011; WAN and Mori 2011; FuJII et al. 2011; MAEDA et al. 2011; SAIto et al. 2011; SAtAKe et al. 2013). These slip models seem to vary depending on the data used in the analysis (e.g. KOKETSU et al. 2011; KOPER et al. 2011; YAO et al. 2011; LAY et al. 2012).

Although this earthquake occurred close to one of the best seismic and geodetic networks in the world (Kinoshita et al. 1998; FuKuyama et al. 1996; Obara et al. 2005; SAGIYA et al. 2000), the slip model does not seem well constrained by the observations because of the station coverage; near-distance stations are located on land, and the trench where the rupture occurred is far from the coast. In addition, the velocity structure in the source region is reported to be very heterogeneous due to the low temperature of the subducting slab (ZHAO et al. 2011). These factors make reliable estimation of the slip distribution difficult, despite the huge amount of available observations.

During the 2011 Tohoku-Oki earthquake, a large slip near the trench was reported to have occurred (e.g. Ito et al. 2011; Lee et al. 2011; SuZUKI et al. 2011; YAGi and FuKahata 2011; SAtaKe et al. 2013). SATO et al. (2011) and Kido et al. (2011) reported a large degree of seafloor deformation above the hypocentral region, and FuJIWARA et al. (2011) reported significant deformation in the trench. These independent observations strongly suggest a large shallow slip, which supports the kinematic slip models with shallow slip near the trench. In the present study, a large slip that occurred at shallow depth is considered in addition to the large slip near the hypocenter. 
In general, at shallow depths near the trench, stress accumulation would be expected to be small because of the low lithostatic stress. In such a situation, a large slip would not be expected, which contradicts the Tohoku-Oki earthquake observations. In fact, based on the focal mechanisms of aftershocks that occurred just after the mainshock, a very low level of total stress is expected to have been present close to the trench. Many intraplate normal-fault aftershocks occurred, which was not the case in this region before the mainshock (AsANO et al. 2011; IDE et al. 2011; Hasegawa et al. 2011). Apparently, these unusual phenomena are associated with the occurrence of a large slip in this region where stress accumulation was low, which led to a drastic change in the stress field.

NodA and Lapusta (2013) proposed a scenario in which thermal pressurization can promote the complete stress release at shallow depths during a rupture. YoshidA and Kato (2011) proposed a depth dependent pore pressure distribution that forced a large slip to occur at shallow depths. These mechanisms might provide a possible explanation for the occurrence of a huge earthquake with a large slip at shallow depths.

In the present study, another possible scenario that can produce a large slip at shallow depths is considered. Numerical simulations are carried out using a spontaneous rupture model in which a bump at seismogenic depths releases a large amount of strain, in order to study how the rupture propagates and produces large slips between the bump and the trench.

\subsection{Fault Model and Initial Conditions}

A boundary integral equation method (HoK and FUKUYAMA 2011) was used for the computation of a spontaneous rupture along a subduction interface with a bump in a homogeneous half-space elastic medium. This method enables spontaneous rupture propagation to be simulated for a model of a nonplanar fault system with a free surface, which is composed of arbitrary triangle elements.

As shown in Fig. 1, a $100 \mathrm{~km} \times 100 \mathrm{~km}$ square fault with a $30^{\circ}$ dip was assumed. The upper edge of the fault is located $0.2 \mathrm{~km}$ below the free surface.

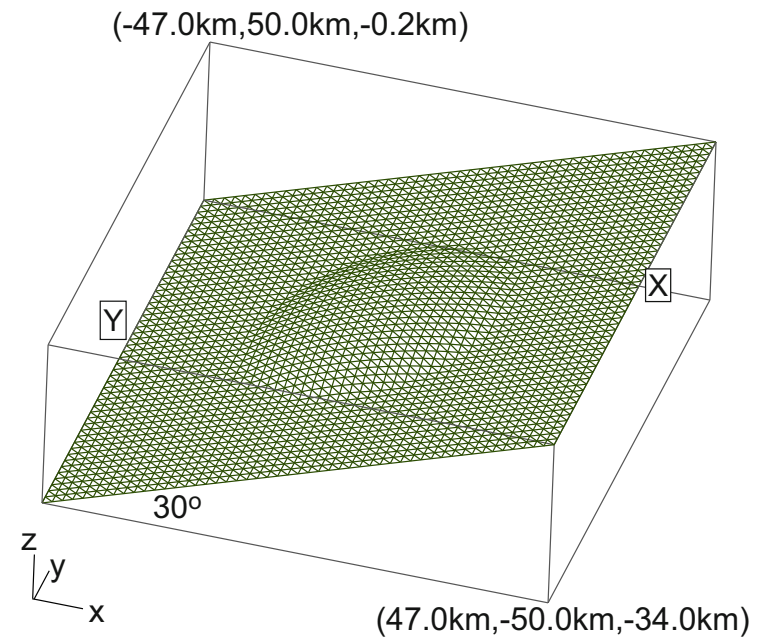

Figure 1

Fault model composed of 5,000 triangular elements. In addition, 5,000 triangular elements (located at $z=0$ ) are used for the free surface (not shown here). Fault dimensions are $100 \mathrm{~km} \times 100 \mathrm{~km}$ and the free surface area is $200 \mathrm{~km} \times 200 \mathrm{~km}$

These values were used in order to avoid numerical instability. A bump region with a radius and height of 25 and $1 \mathrm{~km}$, respectively, is located at the center of the fault. The non-planar fault was discretized into 5,000 triangular elements, each with an area of $2 \mathrm{~km}^{2}$. In addition to the fault elements, 5,000 free surface elements were assigned, covering a $200 \mathrm{~km} \times 200 \mathrm{~km}$ area above the fault. Using the approach of HoK and FuKUYAMA (2011), stress-free boundary conditions were applied to the free surface elements to approximate the free surface boundary conditions there.

It should be noted that the present computations can be scaled to a different model size, as long as the parameter $\kappa=(\Delta \sigma / \mu)\left(L / D_{\mathrm{c}}\right)$ is kept the same, where $\Delta \sigma, \mu, L, D_{\mathrm{c}}$ are dynamic stress drop, rigidity, characteristic length scale, and slip-weakening distance, respectively (e.g. Aоchi et al. 2000; FukuYama and Madariaga 1998; Madariaga and Olsen 2000). For example, to make the bump two times larger, the amount of slip and $D_{\mathrm{c}}$ should be multiplied by two.

The stress change distribution was first calculated by applying a $1-\mathrm{m}$ slip to the region outside the bump. This stress change can be considered as a stress accumulation rate inside the bump during the interseismic period. An additional shear stress of $10 \mathrm{MPa}$ was then applied over the entire fault to 
(a)

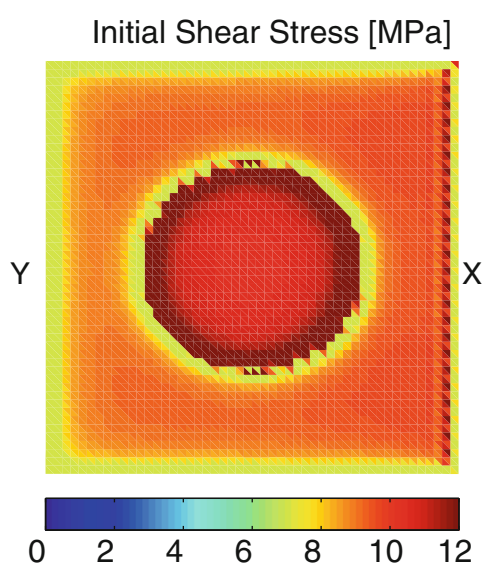

(c)

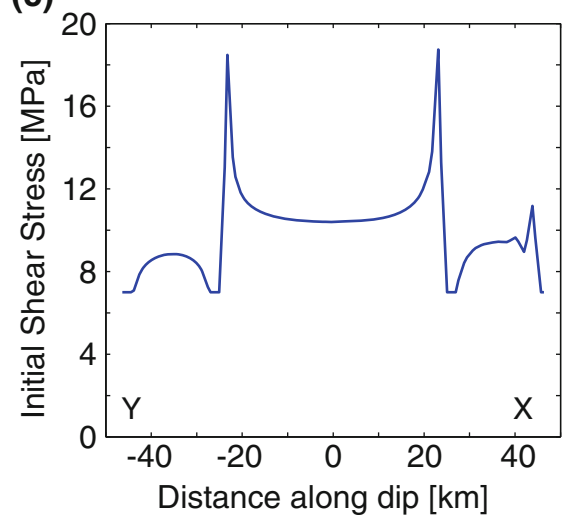

(b) Initial Normal Stress [MPa]

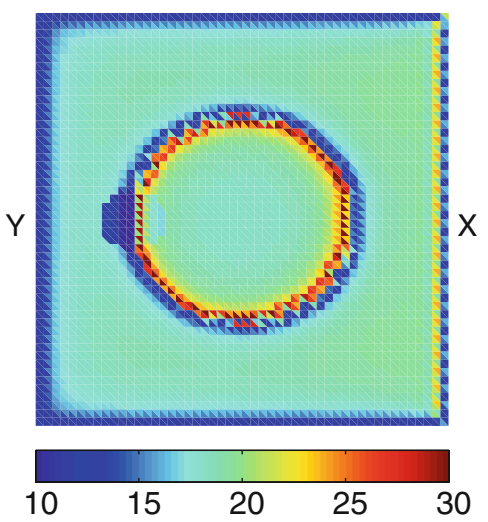

(d)

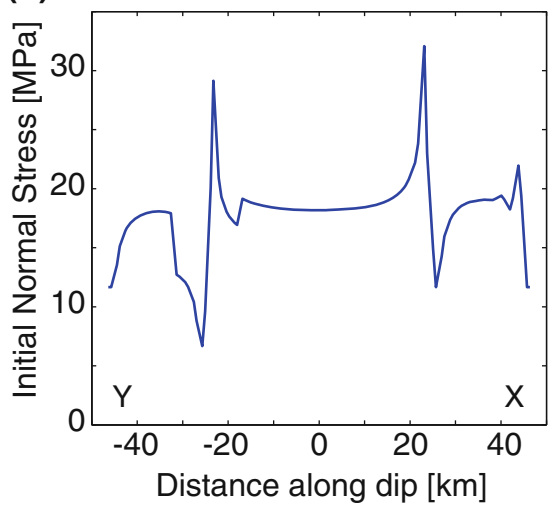

Figure 2

Initial shear (a) and normal (b) stress distribution used for computation of dynamic rupture propagation. Cross sections of initial shear (c) and normal (d) stress along $X-Y$ in (a) and (b) are shown, respectively. It should be noted that the trench is located on side $X$

adjust the absolute stress level. Finally, any region with a stress of $<7 \mathrm{MPa}$ was assigned a value of $7 \mathrm{MPa}$. Although this was carried out mainly to mitigate the edge effect of the stress when computing stress change, $7 \mathrm{MPa}$ is also the frictional shear stress corresponding to the dynamic friction coefficient. Figure 2 shows the initial stress distribution obtained by the above procedure.

As the constitutive relation for the fault, a linear slip-weakening relation (IDA 1972) was used, which is defined by three parameters: static friction coefficient $\left(\mu_{\mathrm{s}}\right)$, dynamic friction coefficient $\left(\mu_{\mathrm{d}}\right)$ and $D_{\mathrm{c}}$. The value of $D_{\mathrm{c}}$ is assumed to be $1 \mathrm{~m}$ for the entire fault, and $\mu_{\mathrm{s}}$ is assumed as 0.6. The strength excess (i.e. the peak shear strength minus the initial shear stress) is taken to be 0.5 and $2 \mathrm{MPa}$ for inside and outside the bump, respectively. The normal stress is then computed using the static shear strength and $\mu_{\mathrm{s}}$. A dynamic shear strength of $7 \mathrm{MPa}$ is also assumed, and $\mu_{\mathrm{d}}$ is determined by the normal stress and the dynamic shear strength (7 MPa). It should be noted that following HoK and FukuYama (2011), both shear and normal stress changes are taken into account during spontaneous rupture propagation, i.e. as the rupture propagates, the stress ratio (the shear stress divided by the normal stress) follows the slipweakening curve.

The rupture was initiated in a circular zone with a radius of $7.5 \mathrm{~km}$, whose center was located at the edge of the bump. Inside the initiation zone, the static shear strength was set equal to the initial stress. When the computation begins, the fracture condition is immediately satisfied inside the initiation zone and the rupture starts to propagate outwards. Finally, to 

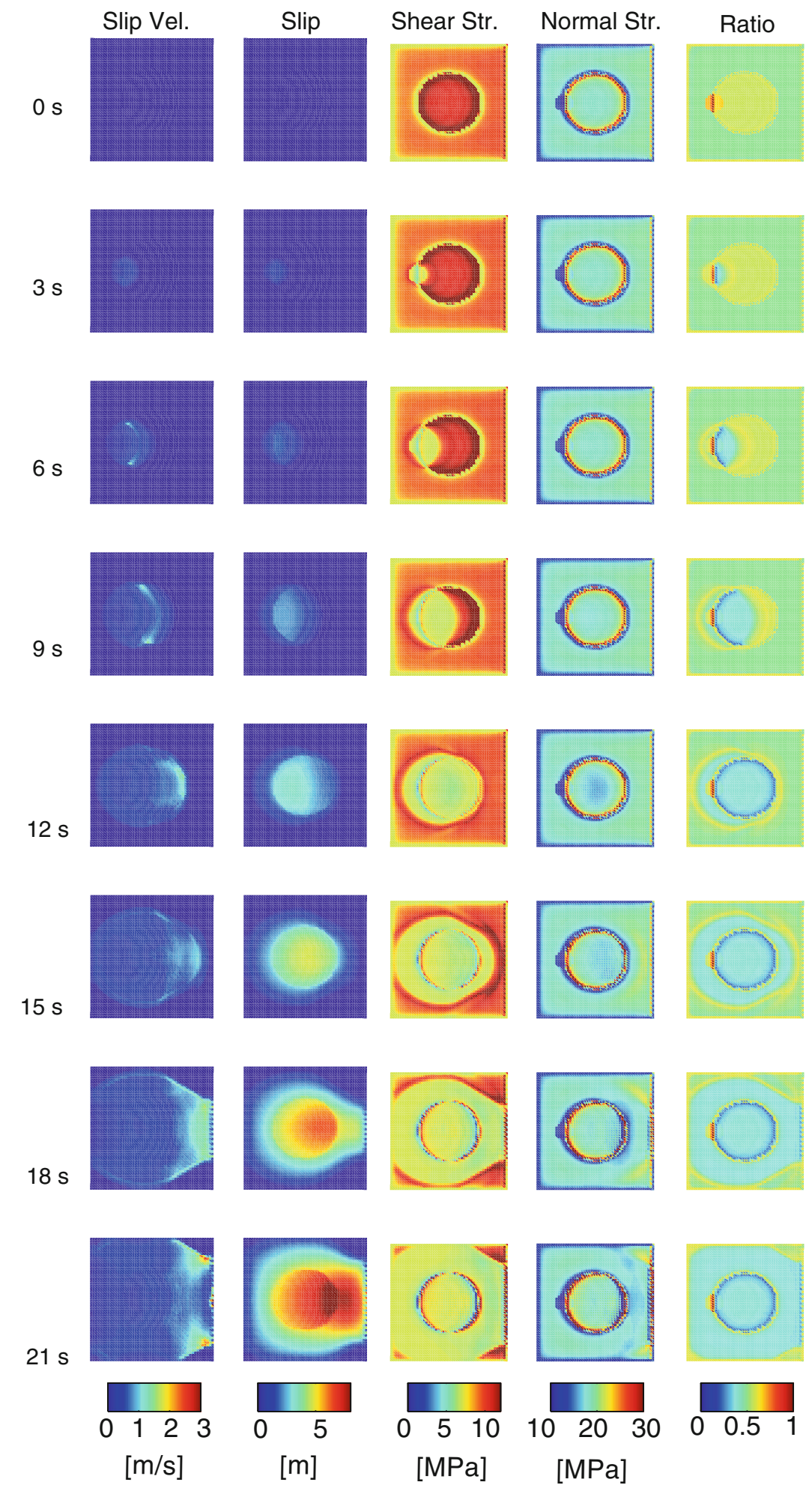

Figure 3

Snapshots of slip velocity, slip, shear stress, normal stress and the ratio of shear stress to normal stress distribution at $3 \mathrm{~s}$ intervals. The trench is located on the right hand side of each panel 
(a)

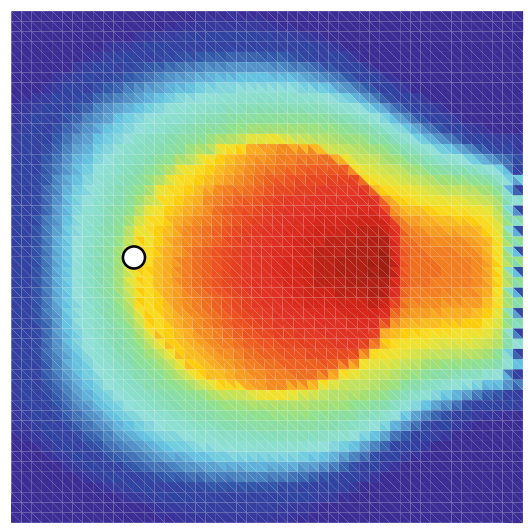

(b)

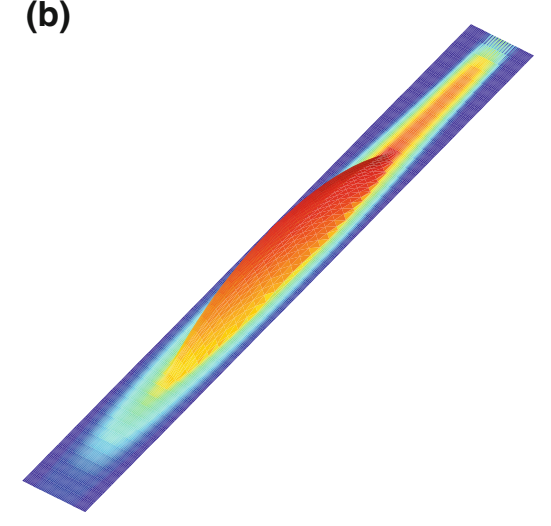

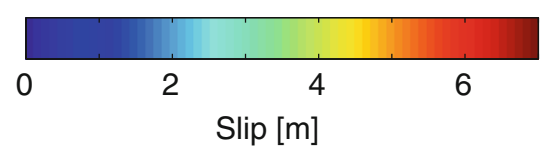

Figure 4

(a) Slip distribution at $18.5 \mathrm{~s}$ for model $\mathrm{d} 12$ and (b) corresponding perspective view. In (a), the trench is located at the right side. The solid white circle in (a) indicates the rupture initiation point

satisfy the Courant-Friedrich-Lewy condition (e.g. Fukuyama and Madariaga 1998), a time step of $0.05 \mathrm{~s}$ was used for this computation.

\subsection{Computation Result}

Three different simulations were carried out, referred to as Models d12, d13 and d14, in which only the location of the initiation was different. Snapshots of the stress and slip distributions for model $\mathrm{d} 12$, where the rupture was initiated at the deeper edge of the bump, are shown in Fig. 3, and the final slip distribution is shown in Fig. 4. From Fig. 3, it can be seen that the rupture propagated inside the bump region (i.e. asperity) first. After the rupture propagated over the entire bump region, it started to extend outside. When the rupture front reached the free surface, slip started to grow between the bump and the trench. The evolution of the slip and stress across the center of the bump perpendicular to the trench is shown in a more quantitative manner in Fig. 5. At about 12-13 s, when the slip is accelerating at the shallow part of the bump, no such acceleration is seen between the bump and the trench (a lower friction area). Quite interestingly, the slip between the bump and the trench becomes large after the rupture has reached the trench (after $17 \mathrm{~s}$ ). This could be due to a hanging wall becoming free at the trench where the rupture intersects the free surface, so that the fault can slip between the bump and the trench without releasing a significant amount of stress (see Fig. 5).

Because of the numerical instability at the trench, it was not possible to compute the entire rupture process, and the simulation does not fully extend to the final stage. This is the reason why the stress does not drop close to the trench in Fig. 5. Since this numerical instability is intrinsic (independent of the numerical parameters) and cannot be solved without introducing artificial damping such as Laplacian smoothing, which might alter the computation result, the computation was stopped just before the numerical instability occurred at the trench.

Figure 6 shows the quasi-final slip distribution for model $\mathrm{d} 13$ and model $\mathrm{d} 14$, in which the rupture initiated at the shallower edge of the bump and at the northernmost edge, respectively. The behavior is the same as that for the deep initiation case. In all cases, a large slip begins to appear when the rupture reaches the trench (free surface). This behavior is similar to that reported by Oglesby et al. (1998). However, they did not discuss the effect of a heterogeneous stress accumulation along the fault. The results of the present simulation show that the existence of a large 

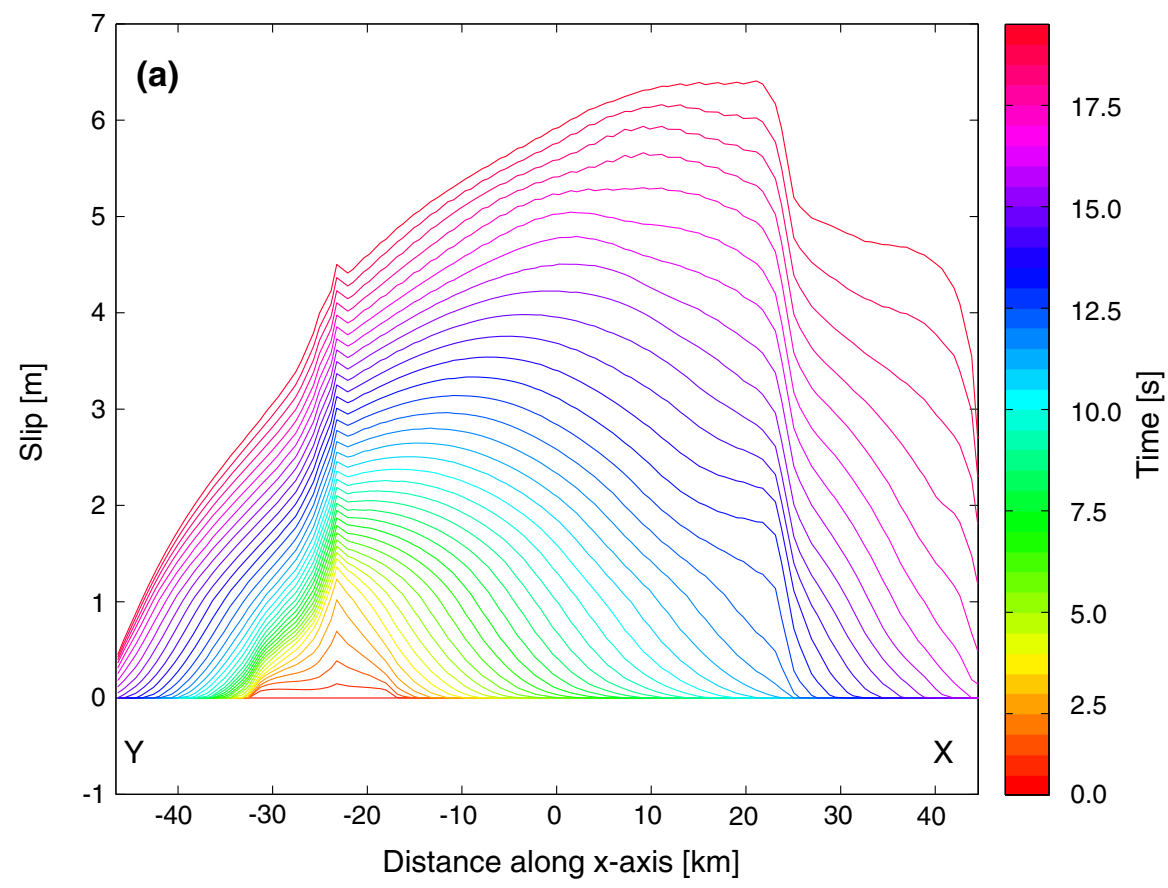

7.5

5.0

2.5

0.0

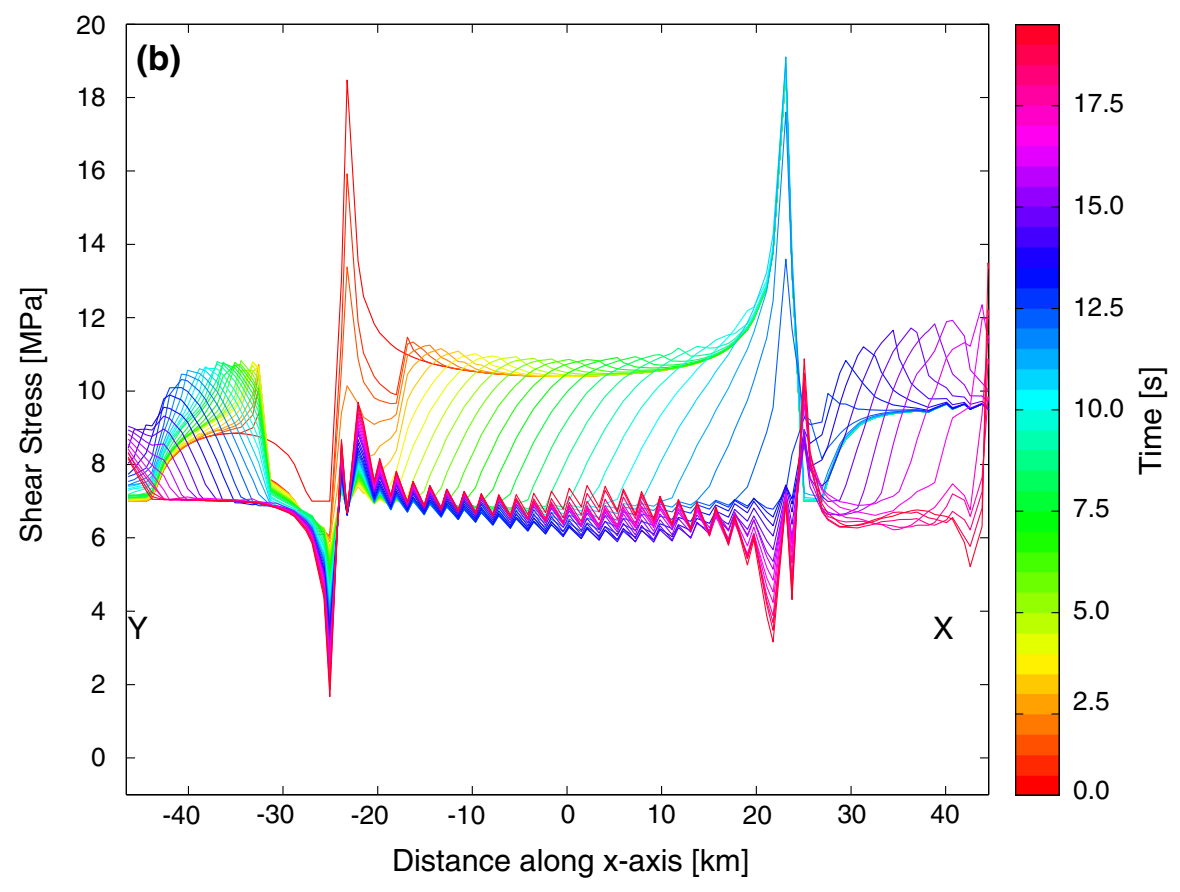

Figure 5

Slip (a) and stress (b) evolution across the cross section of the bump perpendicular to the trench (along $X-Y$ line in Fig. 1). Note that the trench is located on the right side of each graph. Each line is drawn at an interval of $0.5 \mathrm{~s}$

stressed patch (asperity) at a seismogenic depth, which was created by the bump structure, can generate large slip without releasing a significant amount of stress between the asperity and trench. The large slip at a shallow depth could be interpreted as a slip overshoot enhanced by the asperity. 
(a)

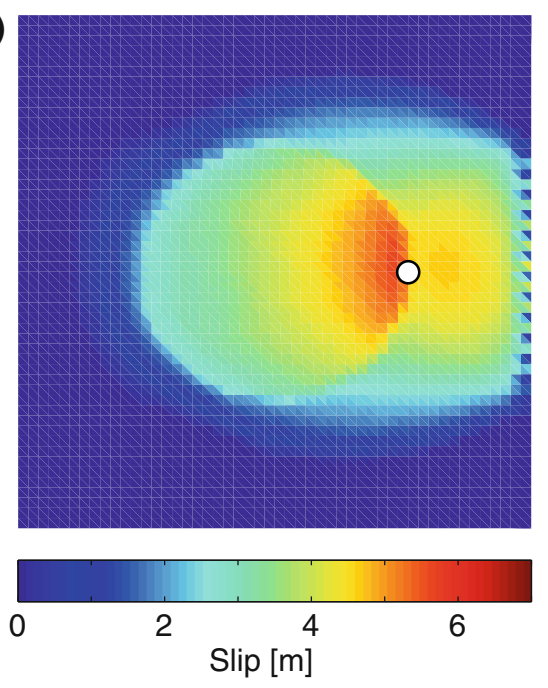

(c)

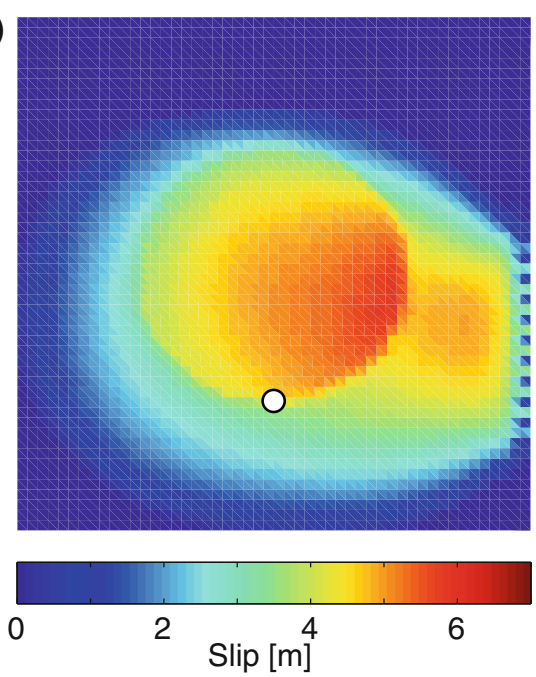

(b)

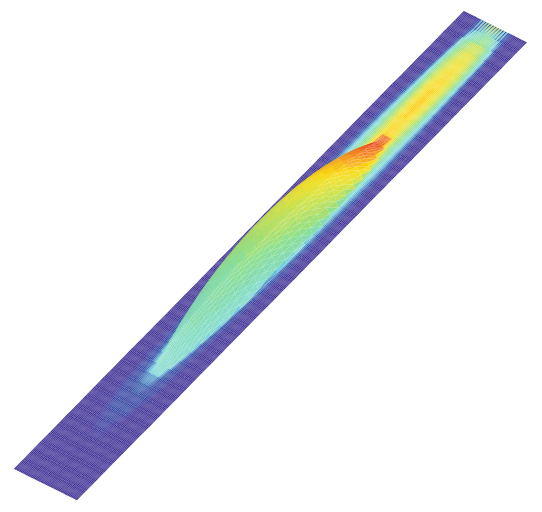

(d)

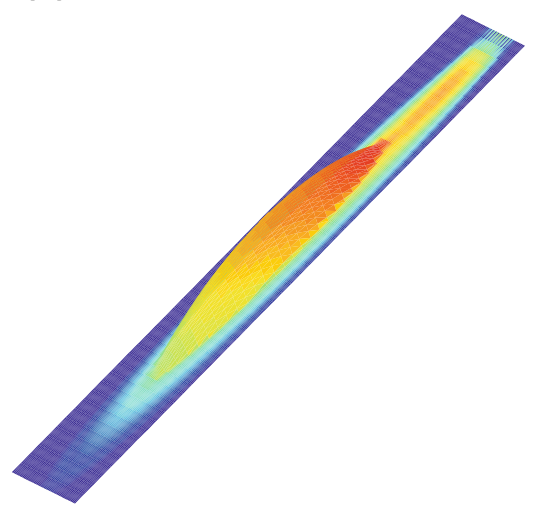

Figure 6

Slip distribution for model $\mathrm{d} 13$ at $15 \mathrm{~s}$ (a) and model d14 at $18 \mathrm{~s}$ (c) and their corresponding perspective views (b, d) are shown. Solid white circles in (a) and (c) indicate the rupture initiation points. In (a) and (c), the trench is located on the right side

\section{Discussion}

As mentioned in the introduction, the slip model for the 2011 Tohoku earthquake includes some uncertainties in the slip distribution at the shallow depth near the trench. In the present study, although the slip becomes large between the bump and the trench, it cannot exceed the amount of slip inside the bump. It should be noted, however, that heterogeneity in the velocity structure was not considered, but instead a homogeneous elastic medium was assumed. Miкumo et al. (1987) pointed out that due to a heterogeneous velocity structure, slip at a shallow part of the fault can be magnified. If a heterogeneous structure was taken into account to achieve a more realistic condition, the slip near the trench could be explained by the proposed model.

It is worth noting that according to the numerical simulation results, a high stress drop region is required at the bottom of the large slip region to generate a large shallow slip near the trench. In the present simulation, the high stress drop patch is modeled as a subducting bump on the plate interface. A similar situation could occur if there was an equivalent structure that could 
store the strain at the bottom of the high slip region (e.g. DuAn 2012). If a high stress region does not exist at the bottom of the high slip region, the interface could not sustain high stress concentration at deep parts of the fault, and aseismic slip would instead occur during the interseismic period.

\section{Conclusion}

Simulations using a model of a plate interface containing a bump were found to be capable of reproducing a region of large slip near the trench, which has been reported for the 2011 Tohoku-Oki earthquake. This indicates that subduction of such an interface could be one possible mechanism producing this earthquake. Since this mechanism is rather general, in any subduction zone where a locked region exists due to subduction of a bump, slip overshoot can occur during coseismic slip, leading to enhanced generation of tsunamis by magnifying deformation near the trench.

\section{Acknowledgments}

We are grateful for the comments by two anonymous reviewers that helped improve the manuscript. This work was supported by the NIED project "Development of Monitoring and Forecasting Technology for Crustal Activity", the NIED-JAMSTEC joint project "High Frequency Source Modeling" and the JST J-Rapid/ANR Flash Japan DYNTOHOKU project (ANR-11-JAPN-0009).

Open Access This article is distributed under the terms of the Creative Commons Attribution License which permits any use, distribution, and reproduction in any medium, provided the original author(s) and the source are credited.

\section{REFERENCES}

Aochi, H., E. Fukuyama and M. Matsu'ura (2000) Spontaneous rupture propagation on a non-planar fault in 3-D elastic medium, Pure Appl. Geophys, 157, 2003-2027.

Asano, Y., T. Saito, Y. Ito, K. Shiomi, H. Hirose, T. Matsumoto, S. Aoi, S. Hori, and S. SeKIGUCHI (2011) Spatial distribution and focal mechanisms of aftershocks of the 2011 off the Pacific coast of Tohoku Earthquake, Earth Planets Space, 63(7), 669-673.
DuAn, B. (2012) Dynamic rupture of the $2011 \mathrm{Mw} 9.0$ Tohoku-Oki earthquake: Roles of a possible subducting seamount, J. Geophys. Res, 117, B05311, doi:10.1029/2011JB009124.

Fuji, Y., K. Satake, S. Sakai, M. Shinohara, and T. Kanazawa (2011) Tsunami source of the 2011 off the Pacific coast of Tohoku earthquake, Earth Planets Space, 63(7), 815-820.

Fujiwara, T., S. Kodaira, T. No, Y. Kaiho, N. TAKahashi, Y. KANEDA (2011) The 2011 Tohoku-Oki earthquake: Displacement reaching the trench axis, Science, 334, 1240, doi:10.1126/ science. 1211554.

Fukuyama, E., M. Ishida, S. Hori, S. Sekiguchi, and S. Watada (1996) Broadband seismic observation conducted under Freesia project, Rep Nat'1 Res Inst Earth Sci Disas Prev, 57, 23-31, http://dil-opac.bosai.go.jp/publication/nied_report/PDF/ 57/57fukuyama.pdf.

Funuyama, E. and R. Madariaga (1998), Rupture dynamics of a planar fault in a 3D elastic medium: Rate- and slip- weakening friction, Bull Seismol Soc Am, 88(1), 1-17.

Hasegawa, A., K. Yoshida, and T. Okada (2011), Nearly complete stress drop in the $2011 \mathrm{M}_{\mathrm{w}} 9.0$ off the Pacific coast of Tohoku earthquake, Earth Planets Space, 63(7), 703-707.

Hashimoto, C., A. Noda, and M. Matsu'ura (2012), The Mw 9.0 northeast Japan earthquake: total rupture of a basement asperity, Geophys J Int, 189, 1-5.

Hok, S. and E. FukuYama (2011), A new BIEM for rupture dynamics in half-space and its application to the 2008 IwateMiyagi Nairiku earthquake, Geophys J Int, 184, 301-324, doi:10. 1111/j.1365-246X.2010.04835.x.

IDA, Y. (1972), Cohesive force across the tip of a longitudinal-shear crack and Grifflth's specific surface energy, J Geophys Res, 77(20), 3796-3805.

Ide, S., A. Baltay, and G. C. Beroza (2011), Shallow dynamic overshoot and energetic deep rupture in the $2011 \mathrm{Mw} 9.0$ Tohoku-Oki earthquake, Science, 332(6036), 1426-1429, doi:10. $1126 /$ science. 1207020 .

IsHII, M. (2011), High-frequency rupture properties of the Mw 9.0 off the Pacific coast of Tohoku Earthquake, Earth Planets Space, 63(7), 609-614.

Ito, Y., T. Tsuj, Y. Osada, M. Kido, D. Inazu, Y. Hayashi, H. Tsushima, R. Hino, and H. Fujimoto (2011), Frontal wedge deformation near the source region of the 2011 Tohoku-Oki earthquake, Geophys Res Lett, 38, L00G05, doi:10.1029/ 2011 GL048355.

Kido, M., Y. Osada, H. Fujimoto, R. Hino, and Y. Ito (2011), Trench-normal variation in observed seafloor displacements associated with the 2011 Tohoku-Oki earthquake, Geophys Res Lett, 38, L24303, doi:10.1029/2011GL050057.

Kinoshita, S. (1998), Kyoshin Net (K-NET), Seismol Res Lett, 69(4), 309-332.

Koketsu, K., Y. Yokota, N. Nishimura, Y. Yagi, S. Miyazaki, Y. FujiI, H. MiYake, S. SAKai, Y. YamanaKa, and T. OKada (2011), A unified source model for the 2011 Tohoku earthquake, Earth Planet Sci Lett, 310, 480-487.

Koper, K. D., A. R. Hutko, T. Lay, C. J. Ammon, H. Kanamori (2011), Frequency-dependent rupture process of the 11 March 2011 Mw 9.0 Tohoku earthquake: Comparison of short-period $\mathrm{P}$ wave backprojection images and broadband seismic rupture models, Earth Planets Space, 63(7), 599-602.

Lay, T., H. Kanamori, C. J. Ammon, K. D. Koper, A. R. Hutko, L. Ye, H. Yue, and T. M. Rushing (2012), Depth-varying rupture 
properties of subduction zone megathrust faults, J Geophys Res, 117, B04311, doi:10.1029/2011JB009133.

Lee, S.-J., B.-S. Huang, M. Ando, H.-C. Chiu, and J.-H. Wang (2011), Evidence of large scale repeating slip during the 2011 Tohoku-Oki earthquake, Geophys Res Lett, 38, L19306, doi:10. 1029/2011GL049580.

Madariaga, R., K. B. Olsen (2000) Criticality of rupture dynamics in 3-D, Pure Appl Geophys, 157, 1981-2001.

Maeda, T., T. Furumura, S. Sakai, and M. Shinohara (2011), Significant tsunami observed at ocean-bottom pressure gauges during the 2011 off the Pacific coast of Tohoku earthquake, Earth Planets Space, 63(7), 803-808.

Mikumo, T., K. Hirahara and T. Miyatake (1987), Dynamic fault rupture process in heterogeneous media, Tectonophys, 144, 19-36.

Miyazaki, S., J. J. McGuire, and P. Segall (2011), Seismic and aseismic fault slip before and during the 2011 off the Pacific coast of Tohoku Earthquake, Earth Planets Space, 63(7), 637-642.

Noda, H. and N. Lapusta (2013), Stable creeping fault segments can become destructive as a result of dynamic weakening, Nature, 493, 518-523, doi:10.1038/nature 11703.

Obara, K., K. Kasahara, S. Hori, and Y. Okada (2005), A densely distributed high-sensitivity seismograph network in Japan: Hi-net by National Research Institute for Earth Science and Disaster Prevention, Rev Sci Inst, 76(2), 021301, 021301-1-021301-12.

Oglesby, D. D., R. J. Archuleta, and S. B. Nielsen (1998), Earthquake on dipping faults: The effects of broken symmetry, Science, 280, 1055-1059.

Ozawa, S., T. Nishimura, H. Suito, T. Kobayashi, M. Tobita, and T. IMAKIREI (2011), Coseismic and postseismic slip of the 2011 magnitude-9 Tohoku-Oki earthquake, Nature, 475, 373-377, doi:10.1038/nature10227.

SAgiYa, T., S. MiYazaki, and T. TADA (2000), Continuous GPS array and present-day crustal deformation of Japan, Pure Appl Geophys, 157(11-12), 2303-2322.

Saito, T., Y. Ito, D. Inazu, and R. Hino (2011), Tsunami source of the 2011 Tohoku-Oki earthquake, Japan: Inversion analysis based on dispersive tsunami simulations, Geophys Res Lett, 38, L00G19, doi:10.1029/2011GL049089.

Satake, K., Y. Fuji, T. Harada, and Y. Namegaya (2013), Time and space distribution of coseismic slip of the 2011 Tohoku earthquake as inferred from tsunami waveform data, Bul Seismol Soc Am, 103(2B), 1473-1492, doi:10.1785/0120120122.
Sato, M., T. Ishikawa, N. Ujihara, S. Yoshida, M. Fujta, M. Mochizuki, A. Asada (2011), Displacement above the hypocenter of the 2011 Tohoku-Oki earthquake, Science, 332, 1395, doi:10.1126/science.1207401.

Shao, G., X. Li, C. Ji, and T. Maeda (2011), Focal mechanism and slip history of the $2011 \mathrm{Mw} 9.1$ off the Pacific coast of Tohoku earthquake, constrained with teleseismic body and surface waves, Earth Planets Space, 63(7), 559-564.

Simons, M. S. E. Minson, A. Sladen, F. Ortega, J. Jiang, S. E. Owen, L. Meng, J.-P. Ampuero, S. Wei, R. Shu, D. V. HelmBerger, H. Kanamori, E. Hetland, A. W. Moore, and F. H. Webi (2011), The 2011 magnitude 9.0 Tohoku-Oki earthquake: Mosaicking the megathrust from seconds to centuries, Science, 332, 1421-1425, doi:10.1126/science.1206731.

Suzuki, W., S. Aoi, H. Sekiguchi, and T. Kunugi (2011), Rupture process of the 2011 Tohoku-Oki mega-thrust earthquake (M9.0) inverted from strong-motion data, Geophys Res Lett, 38, L00G16, doi:10.1029/2011GL049136.

WAN, D. and J. Mori (2011), Rupture process of the 2011 off the Pacific coast of Tohoku earthquake (Mw 9.0) as imaged with back-projection of teleseismic P-waves, Earth Planets Space, 63(7), 603-607.

YAGI, Y. and Y. Fukahata (2011), Rupture process of the 2011 Tohoku-oki earthquake and absolute elastic strain release, Geophys Res Lett, 38, L19307, doi:10.1029/2011GL048701.

Yao, H., P. Gerstoft, P. M. Shearer, and C. Mecklenbräuker (2011), Compressive sensing of the Tohoku-Oki Mw9.0 earthquake: Frequency dependent rupture modes, Geophys Res Lett, 38, L20310, doi:10.1029/2011GL049223.

Yoshida, S., and N. Kato (2011), Pore pressure distribution along plate interface that causes a shallow asperity of the 2011 great Tohoku-oki earthquake, Geophys Res Lett, 38, L00G13, doi:10. 1029/2011GL048902.

Yoshida, Y., H. Ueno, D. Muto, and S. Aoki (2011) Source process of the 2011 off the Pacific coast of Tohoku earthquake with the combination of teleseismic and strong motion data, Earth Planets Space, 63(7), 565-569.

Zhao, D., Z. Huang, N. Umino, A. Hasegawa, and H. Kanamori (2011), Structural heterogeneity in the megathrust zone and mechanism of the 2011 Tohoku-oki earthquake (Mw 9.0), Geophys Res Lett, 38, L17308, doi:10.1029/2011GL048408. 